mable gas has been present in the workings. The reports of the Inspectors of Mines bear ample testimony to the correctness of this statement. It has therefore been customary in the absence of any other tenable hypothesis to assume that a large volume of firedamp had been suddenly poured into the workings. But these so-called "outbursts of gas" are entirely unknown in some localities in which great explosions have occurred; and therefore it is much to be marvelled at that some other explanation was not at least sought for.

In September, I844, before the appointment of inspectors of mines, Lyell and Faraday were sent to Haswell Colliery by the Home Secretary to report on an explosion that had just taken place there. I am unable to quote from their official report, but I am firmly convinced that the following sentences taken from their article on the subject in the Phil. Mag. I 845 , is the true key to a solution of the problem as regards both the mode of occurrence and means to be used for the purpose of avoiding great explosions in future; and, moreover, I believe that it has been highly unfortunate, both for the cause of the miner and his employer, that these two philosophers were not induced to prosecute their investigations further than they did.

The sentences referred to are these:-" In considering the extent of the fire for the moment of explosion, it is not to be supposed that firedamp is its only fuel; the coal-dust swept by the rush of wind and flame from the floor, roof, and walls of the works, would instantly take fire and burn, if there were oxygen enough in the air to support its combustion; and we found the dust adhering to the face of the pillars, props, and walls in the direction of, and on the side towards, the explosion, increasing gradually to a certain distance as we neared the place of ignition. This deposit was in some parts half an inch, and in others almost an inch thick; ${ }^{1}$ it adhered together in a friable coked state; when examined with the glass it presented the fused round form of burnt coal-dust, and when examined chemically, and compared with the coal itself reduced to powder, was found deprived of the greater portion of the bitumen, and in some cases entirely destitute of it."

About three years ago M. Vital, Ingénieur des Mines in France, showed that a flame resembling that produced by a blasting stiot which blows out the tamping is greatly lengthened in an atmosphere containing a cloud of coaldust; and soon afterwards the writer ascertained that air containing a small proportion of firedamp (less than one per cent. by volume) becomes highly inflammable when coal-dist is mixed with it.

These discoveries complete what Lyell and Faraday began, and show how explosions of any conceivable magnitude may occur in mines containing dry coal-dust. A blasting shot or a small local explosion of firedamp, or a naked light exposed when a cloud of coal-dust is raised up by a fall of roof in air already containing a little fire. damp is sufficient to initiate them, and, when once they are begun, they become self-sustaining.

These remarkable facts are either not yet sufficiently. well known or their true significance is not yet fully appreciated. In conclusion I may state that out of many

$x$ In the reports of the Inspectors of Mines, human bodies, timber, and coal, are described as being charred or burnt where they are covered with this deposit,-W. G. hundred collieries known to me there is not, to my knowledge, a single damp one in which a great explosion has happened; while, on the other hand, there is a considerable number of very dry ones in which explosions causing the deaths of from 12 to 178 men at a time have occurred.

W. GaIiLOWAY

\section{THE SUN'S PHOTOSPHERE}

R. JANSSEN has just made a communication to the French Academy of Sciences, which will be received with interest, not only by students of solar physics, but by all who follow the various triumphs achieved by modern scientific methods. It seems a paradox that discoveries can be made depending on the appearance of the sun's surface by observations in which the eye applied to the telescope is powerless; but this is the statement made by Dr. Janssen himself, and there is little doubt that he has proved his point.

Before we come to the discovery itself let us say a little concerning Dr. Janssen's recent endeavours. Among the six large telescopes which now form a part of the equipment of the new physical observatory recently established by the French government at Meudon, in the grounds of the princely Château, there is one to which Dr. Janssen has recently almost exclusively confined his attention. It is a photoheliograph giving images of the sun on an enormous scale-compared with which the pictures obtained by the Kew photoheliograph are, so to speak, pigmies, while the perfection of the image and the photographic processes employed are so exquisite, that the finest mottling on the sun's surface cannot be overlooked by those even who are profoundly ignorant of the interest which attaches to it.

This perfection and size of image have been obtained by Dr. Janssen by combining all that is best in the principles utilised in one direction by Mr. De la Rue, and in the other by Mr. Rutherfurd. In the Kew photoheliograph, which has done such noble work in its day that it will be regarded with the utmost veneration in the future, we have first a small object-glass corrected after the manner of photographic lenses, so as to make the socalled actinic and the visual rays coincide, and then the image formed by this lens is enlarged by a secondary magnifier constructed, though perhaps not too accurately, so as to make the actinic and visual rays unite in a second image on a prepared plate. Mr. Rutherfurd's beautiful photographs of the sun were obtained in a somewhat different manner. In his object-glass he discarded the visual rays altogether and brought only the blue rays to a focus, but when enlargements were made an ordinary photographic lens-that is, one in which the blue and yellow rays are made to coincide-was used.

Dr. Janssen uses a secondary magnifier, but with the assistance of M. Pragmowski he has taken care that both it and the object-glass are effective only for those rays which are most strongly photographic. Nor is this all; he has not feared largely to increase the apertures and focal length, so that the total length of the Kew instrument is less than one-third of that in operation in Paris.

The largely-increased aperture which Dr. Janssen has given to his instrument is a point of great importance. In the early days of solar photography the aperture used was small, in order to prevent over-exposure. It was 
soon found that this small aperture, as was to be expected, produced poor images in consequence of the diffraction effects brought about by it. It then became a question of increasing the aperture while the exposure was reduced, and many forms of instantaneous shutters have been suggested with this end in view. With these, if a spring be used, the narrow slit ${ }^{1}$ which flashes across the beam to pay the light out into the plate changes its velocity during its passage as the tension of the spring changes. Of this again Dr. Janssen has not been unmindful, and he has invented a contrivance in which the velocity is constant during the whole length of run of the shutter.

By these various arrangements the plates have now been produced at Meudon of fifteen inches diameter, showing details on the sun's surface of less than one second of arc.

So much for the modus operandi. Now for the branch of solar work which has been advanced.

It is more than fifteen years ago since the question of the minute structure of the solar photosphere was one of the questions of the day. The so-called "mottling" had long been observed. The keen-eyed Dawes had pointed out the thatch-like formation of the penumbra of spots, when one day $\mathrm{Mr}$. Nasmyth announced the discovery that the whole sun was covered with objects resembling willow leaves, most strangely and effectively interlaced. I here quote from Sir John Herschel. ${ }^{2}$

"According to his observations, made with a very fine telescope of his own making, the bright surface of the sun consists of separate, insulated, individual objects or things, all nearly or exactly of one certain definite size and shape, which is more like that of a willow leaf, as he describes them, than anything else. These leaves or scales are not arranged in any order (as those on a butterfly's wing are), but lie crossing one another in all directions, like what are called spills in the game of spilikins; except at the borders of a spot, where they point for the most part inwards, towards the middle of the spot, presenting much the sort of appearance that the small leaves of some water-plants or seaweeds do at the edge of a deep hole of clear water. The exccedingly definite shape of these objects; their exact similarity one to another; and the way in which they lie across and athwart each other (except where they form a sort of bridge across a spot, in which case they seem to affect a common direction, that, namely, of the bridge itsclf), all these characters seem quite repugnant to the notion of their being of a vaporous, a cloudy, or of a fluid nature. Nothing remains but to consider them as separate and independent sheets, flakes, or scales, having some sort of solidity. And these flakes, be they what they may, and whatever may be said about the dashing of meteoric stones into the sun's atmosphere, \&c., are evidently the immediate sources of the solar light and heat, by whatever mechanism or whatever processes they may be enabled to develop, and as it were elaborate these elements from the bosom of the non-luminous fluid in which they appear to float. Looked at in this point of view, we cannot refuse to regard them as organisms of some peculiar and amazing kind ...."

Here, then, was a discovery with a vengeance! and absolute endorsement from the man above all others who

I I have recently been making some cxperiments with a view of getting rid of the narrow aperture in general use, as it has appeared to me that the diffraction effects produced by it must be as injurious to definition as those due to a small object-glass. I have found that a circular aperture, allowing the whole beam to be flashed on the plate in conjunction with a plate of optically pure yellow glass nearly in contact with the photographic plate can be used without over-exposure.

2 "Familiar Lectures," p. 87. had a right to express an opinion. Nevertheless, the organisms have since disappeared, and the work of many careful observers has established that the mottling on the sun's surface is due to dome-like masses, and that the "thatch" of the penumbra is due to these dome-like masses being drawn, either directly or in the manner of a cyclone, towards the centre of the spot. In fact the "pores" in the interval between the domes are so many small spots, while the faculæ are the higher levels of the cloudy surface. The fact that faculae are so much better seen near the limb proves that the absorption of the solar atmosphere rapidly changes between the levels reached by the upper faculæ and the pores.

These masses are in all probability due to a rapid increase of pressure in the portion of the solar atmosphere occupied by the photosphere; we know, or think we know, that they are not due to reduction of temperature.

Thus much presumed we now come to Dr. Janssen's discovery.

An attentive examination of his photographs shows that the surface of the photosphere has not a constitution uniform in all its parts, but that it is divided into a series of figures more or less distant from each other, and prew senting a peculiar constitution. These figures have contours more or less rounded, often very rectilinear, and generally resembling polygons. The dimensions of these figures are very variable; they attain sometimes a minute and more in diameter.

While in the interval of the figures of which we speak the grains are clear, distinctly terminated, although of very variable size, in the interior the grains are as if half effaced, stretched, strained; for the most part, indeed, they have disappeared to make way for trains of matter which have replaced the granulation. Everything indicates that in these spaces, as in the penumbre of spots, the photospheric matter is submitted to violent movements which have confused the granular elements.

In an article recently contributed by Dr. Hunter and myself to the Nineteenth Century, ${ }^{1}$ the following passage occurs :-

"The spots may be taken as a rough index of solar energy, just as the rainfall may be taken as a convenient indication of terrestrial climate. They are an index but not a measure of solar activity; and their absence indicates a reduction, not the cessation, of the sun's energy. Whether this reduction means one in a hundred or one in a thousand we do not know."

With the same idea in his mind Dr. Janssen points out that this fact throws light upon the forms of solar activity, and shows that that activity, in the photosphere, is always very great, although no spot appears on the surface.

We haye already referred to the paradox that the sun's appearance can now be best studied without the eye applied to the telescope. This is what Dr. Janssen says on that point.

The photospheric network cannot be discovered by optical methods applied directly to the sun. In fact, to ascertain it from the proofs, it is necessary to employ glasses which enable us to embrace a certain extent of the photographic image. Then if the magnifying power is quite suitable, if the proof is quite pure, and especially if I "Sun-spols and Famines," Nineteenth Century, November, r877, p. 584. 
it has received rigorously the proper exposure, it will be seen that the granulation has not everywhere the same distinctness, that the parts consisting of well-formed grains appear as currents which circulate so as to circumscribe spaces where the phenomena present the aspect we have described. But to establish this fact, it is necessary to embrace a considerable portion of the solar disc, and it is this which it is impossible to realise when we look at the sun in a very powerful instrument the field of which is, by the very fact of its power, very small. In these conditions we may very easily conclude that there exist portions where the granulation ceases to be distinct or even visible ; but it is impossible to suppose that this fact is connected with a general system.

We have written enough to show that when the daily history of the sun comes to be recorded another method and another point of view have now been added as the first fruits of Dr. Janssen's labours in his new observatory.

\section{J. NORMAN LOCKyer}

\section{FOWNES" “MANUAL OF CHEMISTRY"}

Forenes' Manual of Chemistry. Vol. II. Chemistry of Carbon Compounds, or Organic Chemistry. Twelfth Edition. By H. Watts, B.A., F.R.S. (London: Churchill, I877.)

RGANIC chemistry is now progressing with such rapid strides, that a work on this subject becomes antiquated, at least in some parts, in the course of a few years. A new edition of a well known and favourite book must therefore be most welcome to students of this branch of chemical science, and more so when edited by a man whom we may justly call "the English Gmelin."

The old familiar, bulky Fownes has now been divided into two handy volumes, enabling the editor to devote the same space to the carbon compounds as to inorganic chemistry.

The arrangement of the subject is in principle almost the same as in the last edition; organic compounds being divided into hydrocarbons, alcohols, ethers, amido-compounds, organo-metallic bodies, acids, \&c., the compounds of each group being arranged in homologous series.

Physiological chemistry is omitted, and this must be considered as an improvement, as that branch of chemical science now requires special treatment in a separate work.

The name of the author is a sufficient guarantee for the soundness of the knowledge which this book imparts, and we hope to see it soon in the hands of numerous students who will find it a most useful and trustworthy guide, embracing as it does the most important recent researches. The book is singularly free from misprints, and the few which we have found can be easily corrected by a student who is accustomed to think for himself.

As a reviewer is expected to point out any faults, we will do so, but "sine iræe et studia," and only for the benefit of the students who will largely use this work.

Thus we miss an account of the normal sulphuric ethers, which are found by the action of sulphuryl chloride, or oxychloride on the alcohols and phenols. Perhaps these parts were written before the researches we allude to were published, and the same may be the case with phenyl-sulphuric acid, and its homologues, compounds which possess such interest both for the chemist and physiologist. To lactide, the author still assigns the old formula $\mathrm{C}_{3} \mathrm{H}_{4} \mathrm{O}_{2}$, although Henry has proved, by determining its vapour density, that its molecular formula is $\mathrm{C}_{6} \mathrm{H}_{8} \mathrm{O}_{4}$. On page 285 we find a statement which might lead a beginner in practical work to disappointment, it is there said that "crude acetyl chloride is purified by heating it with water and dilute soda solution." "Quandoque bonus dormitat Homerus."

We were much pleased to find that Mr. Watts has given particular attention to the study of isomerism, especially among the derivatives of benzene, and he justly says in the preface: "This part of the subject is here presented in a form in which it has not yet appeared in any English publication, except in the fournal of the Chemical Society."

Speaking of the disubstitution products of benzene, the following definition is given: "A di-derivative of benzene is para-, ortho-, or meta-, according as it can give rise to, or be formed from, one, two, or three tri-derivatives. This definition is, however, incomplete, and only holds good if in the di.derivative the substituting elements or radicals are the same. For it is easily seen that, to take the most simple case, a para-compound containing two different groups such as paranitrobromobenzene can give rise to or be formed from two different amidonitrobromobenzenes. The oversight is, however, a matter of small importance, and an attentive student will not be led astray by it.

The theory of structure or position which $\mathrm{Mr}$. Watts treats so fully has been lately attacked by eminent chemists who seem to overlook or forget the great impulse which this theory has given to the progress of organic chemistry. The "modern chemists," as they sneeringly have been called, know well enough that the structural formulæ which they use do not pretend to give a picture of the real position of atoms in space, and do not mean more than the parallelogram of forces in mechanics, i.e., they only express the manner in which the different forces of the atoms attract each other. They fully understand that their present theory, with the progress of science will have to undergo many modifications, and it is not a dogma, but will stand or fall on its own merits.

The opponents of the modern school remind us of the last followers of the phlogistic theory who got hold of any fact which the antiphlogistonists were not able to explain as a proof that the latter were in the wrong. We can easily imagine how pleased Priestley was when it was found that when heating certain metallic calces with charcoal an inflammable air was formed, whereas, according to Lavoisier's school, only carbonic acid could be produced. Just in the same way the opponents of the structural theory point out that the existence of four lactic acids is incompatible with it; and Mr. Watts himself, although a strong adherent of the theory of structure, shirks the discussion of this point, and rusticates one of the four in a foot-note, in which he expresses his doubts as to its existence.

The recent researches of Wislicenus, however, hardly leave any doubt that four such acids exist. We must confess that we are not able to explain the difference between hydracrylic acid and ethenelactic acid, and quite agree with $\mathrm{Mr}$. Watts that Wislicenus' explanation of the 